\title{
Improved Carrier Transport in Perovskite Solar Cells Probed by Femtosecond Transient Absorption
}

\section{Spectroscopy}

Efthymis Serpetzoglou ${ }^{\S, \|}$, Ioannis Konidakis, ${ }^{*,}$, George Kakavelakis ${ }^{ \pm, \#}$, Temur Maksudov ${ }^{ \pm, \#}$, Emmanuel Kymakis ${ }^{*, \pm}$, Emmanuel Stratakis ${ }^{* \$, \#}$

${ }^{\S}$ Institute of Electronic Structure and Laser (IESL), Foundation for Research and TechnologyHellas (FORTH), 71110, Heraklion, Crete, Greece

${ }^{ \pm}$Center of Materials Technology and Photonics, Electrical Engineering Department, Technological Educational Institute (TEI) of Crete, 71004, Heraklion, Crete, Greece "Physics Department, University of Crete, GR 71003 Heraklion, Crete, Greece "Department of Materials Science and Technology, University of Crete, Greece, 71003, Heraklion, Crete, Greece

\section{Corresponding Authors}

*+30 2810-391835. E-mail: ikonid@iesl.forth.gr

*+30 2810-391274. E-mail: stratak@iesl.forth.gr

*+30 2810-379895. E-mail: kymakis@ staff.teicrete.gr 


\section{Abstract}

$\mathrm{CH}_{3} \mathrm{NH}_{3} \mathrm{PbI}_{3}$ perovskite thin films have been deposited on glass/indium tin oxide (ITO)/Hole Transport Layer (HTL) substrates, utilizing two different materials as the HTLs. In the first configuration the super hydrophilic polymer poly (3,4-ethylenedioxythiophene)-poly (styrenesulfonate), known as PEDOT:PSS, was employed as the HTL material, while on the second case the non-wetting poly (triarylamine) semiconductor polymer, known as PTAA was used. It was found that when PTAA is used as HTL material the averaged power conversion efficiency (PCE) of the perovskite solar cells remarkably increases from $12.60 \%$ to $15.67 \%$. In order to explore the mechanism behind this enhancement, the aforementioned perovskite/HTL arrangements were investigated by time resolved transient absorption spectroscopy (TAS) performed under inert conditions. By means of TAS, the charge transfer, carrier trapping and holes injection dynamics from the photo-excited perovskite layers to the HTL can be directly monitored via the characteristic bleaching profile of the perovskite at $\sim 750 \mathrm{~nm}$. TAS studies revealed faster relaxation times and decay dynamics when the PTAA polymer is employed, that potentially account for the enhanced PCE observed. The TAS results are correlated with the structure and crystalline quality of the corresponding perovskite films, investigated by scanning electron microscopy (SEM), X-ray diffraction (XRD), atomic force microscopy (AFM), microphotoluminescence $(\mu \mathrm{PL})$ and transmittance spectroscopy. It is concluded that TAS is a benchmark technique for the understanding of the carrier transport mechanisms in PSCs and constitutes a figure-of-merit tool towards their efficiency improvement.

Keywords: Perovskite solar cells, hole transport layer, transient absorption spectroscopy, charge transfer dynamics, recombination rates. 


\section{Introduction}

Organic-inorganic lead halide perovskites have attracted significant attention during the last decade, due to their application in various fields, such as next generation photovoltaics, light emitting devices, photodetectors, lasers, and LEDs. ${ }^{1-5}$ Much of this attention originates from their outstanding properties, namely, the medium optical bandgap and strong absorption coefficients and the long carrier diffusion lengths, as well as, the low recombination losses and bandgap tunability. ${ }^{6-9}$ In terms of recent photovoltaic technology, perovskite light absorber films gain tremendous scientific interest due to their potential of being established as an efficient, flexible, while being a large scale low cost material. Indicatively, since the invention of perovskite solar cells (PSCs), the power conversion efficiencies (PCEs) have been rapidly boosted from $\sim 4 \%$ up to $\sim 22 \%$ in small area cells $\left(\sim 1 \mathrm{~cm}^{2}\right)$ within a decade. ${ }^{10-13}$ The respective record PCE for large area perovskite solar modules $\left(>50 \mathrm{~cm}^{2}\right)$ has been recently reported to be $12.6 \%{ }^{14}$ These remarkable achievements render perovskite absorbers as strong contenders for being a major part of the state-of-the-art next generation commercial available photovoltaic technology. Despite the remarkable progress on the field, more knowledge is still required until the achievement of costeffective commercialization of the PSCs technology.

In this context, recent scientific approaches focus on two major aspects. First, introduce ways and cell architectures in order to maximize the PCEs of PSCs, while at the same time, resolving the issues of their stability upon humidity, ${ }^{15,16}$ and elongated light exposure. ${ }^{17,18}$ Over the years several approaches have been adopted in order to tackle the aforementioned drawbacks, while optimizing PCE. Numerous studies focus on the composition and synthesis protocols of the perovskite itself, as it is generally acknowledged that the crystalline quality plays a fundamental role on the device performance. ${ }^{11-13,19-23}$ As for instance, a variety of single methyl ammonium 
lead halide perovskite absorbers of the formula $\mathrm{CH}_{3} \mathrm{NH}_{3} \mathrm{PbX}$ have been employed, as well as, various mixed halide structures based on the same formula in which a second inorganic anion is introduced, i.e. $\mathrm{CH}_{3} \mathrm{NH}_{3} \mathrm{PbI}_{3-\mathrm{x}} \mathrm{X}_{\mathrm{x}}$, where $\mathrm{X}$ is $\mathrm{Cl}$ or $\mathrm{Br}^{12,13}$ Along similar lines, other studies emphasize the importance of various fabrication procedures that include among others, one-step and two-step deposition protocols, ${ }^{10,24,25}$ crystal formation via solution and vapor deposition processes, ${ }^{4,526-28}$ and rapid laser annealing crystallization techniques. ${ }^{22,23}$

On a rather different manner, aiming to enhance efficiency while improving device lifetime, significant attention has been paid on the selection of suitable hole transport layer (HTL) and electron transport layer (ETL) conductive materials. Among the available choices for the HTL component, are the polymers poly (3,4-ethylenedioxythiophene)-poly (styrenesulfonate), known as PEDOT:PSS, and the poly (triarylamine), known as PTAA, while [6,6]-Phenyl-C61-butyric acid methyl ester, known as PCBM, is widely used as an ETL. The interactions between HTL/perovskite and perovskite/ETL interfaces are crucial in terms of minimizing factors that are known to reduce PSCs efficiency, such as the formation of light activated charge states and ion migration in the perovskite crystal lattice. ${ }^{18,29,30}$ Aiming to resolve these alarming degradation sources, recent studies report on the appropriate doping of PTAA and PCBM polymeric conductors with ingredients that increase conductivity properties while improving stability. ${ }^{31,32}$ For the same objective, other studies focus directly on the effect of HTL and ETL material properties and characteristics on the device performance and stability. ${ }^{12,33-35}$ Among other reports, it was recently highlighted by $\mathrm{Bi}$ et al. that the employment of the non-wetting PTAA polymer as HTL significantly improves the efficiency of the PSC devices. ${ }^{35}$ However, no clear evidence on the origins of such efficiency improvement has been reported to date. 
In this work, we thoroughly correlate the obtained morphological differences of the perovskite active layer film upon employing different HTLs with the charge extraction processes and the corresponding transient decay dynamics that are probed by means of femtosecond time-resolved transient absorption spectroscopy (TAS). These processes are well-acknowledged to play a fundamental role on the performance of PSC devices of this configuration. It is firstly revealed, that the morphology of the perovskite film strongly depends on the type of HTL material. More importantly, it is discovered that upon using a more hydrophobic HTL polymer, not only the morphology of the perovskite film improves, but even more strikingly, the HTL/perovskite charge extraction processes are accelerated, while on the same time the corresponding recombination processes become slower. Both these factors favor significantly the PCE of the PSCs in question, and thus, our recent findings point out one plausible approach towards maximizing the efficiency of such devices. Although TAS has been recently employed for the study of the transport properties in PSCs, ${ }^{7,33,36-39}$ the measurements were performed in ambient air, which are known to be detrimental for the perovskite layer, mostly due to its instability against humidity. ${ }^{15,16}$ In the present case, however, TAS measurements were performed entirely under inert conditions. In particular, we compare two types of PSC devices using identical $\mathrm{CH}_{3} \mathrm{NH}_{3} \mathrm{PbI}_{3}$ absorber, but a hydrophilic, PEDOT:PSS, and a more hydrophobic PTAA HTL respectively. TAS measurements reveal faster charge carrier dynamics and relaxation component times and slower recombination processes for the PTAA/perovskite, relatively to the corresponding PEDOT:PSS/perovskite architecture, which could account for the enhanced PCE of the device in which the former configuration is used. The TAS findings are further complemented by electron and atomic force microscopy, as well as photoluminescence and transmittance spectroscopy studies, aiming to shed light on the effect of the applied HTL 
material on the perovskite layer structure and morphology. It is evidenced that such unique correlation of carrier relaxation dynamics and structural morphology, demonstrated here, could be beneficial towards efficiency enhancement of state-of-the-art PSCs.

\section{Experimental Section}

\section{Device fabrication}

All PSCs of this study were prepared on prepatterned indium tin oxide (ITO) coated glass substrates (Naranjo Substrates) with dimensions of $20 \times 15 \mathrm{~mm}$ and sheet resistance of $\sim 20 \Omega \mathrm{sq}^{-1}$. In order to remove any possible impurities, prior to the HTL deposition, a three-step cleaning process with deionized water, acetone, and isopropanol is performed to the ITO/glass substrates. ${ }^{32}$ Following this, the substrates were placed inside an ultraviolet ozone cleaner in order to increase surface hydrophilicity of ITO coated glass, while removing organic residues. Afterwards, the HTL was deposited on the ITO/glass substrate. For the case of PEDOT:PSS, the polymer was spin casted on the ITO surface from an aqueous solution (4000 rpm, $60 \mathrm{~s})$. Such spin coating process resulted to a layer thickness of $\sim 30 \mathrm{~nm}$. Subsequently, the sample was baked for 15 minutes in ambient conditions and 30 more minutes inside a nitrogen-filled glove box at $120{ }^{\circ} \mathrm{C}$. For samples where PTAA was used as HTL, a solution of PTAA powder in toluene $\left(10 \mathrm{mg} \mathrm{ml}^{-1}\right)$ doped with $1.5 \mathrm{wt} \%$ tetrafluoro-tetracyanoquinodimethane (F4-TCNQ) was prepared and spin coated at $4000 \mathrm{rpm}$ for 35 second on the ITO surface. Upon HTL deposition the substrates were allowed to cool down to room temperature. The films of $\mathrm{CH}_{3} \mathrm{NH}_{3} \mathrm{PbI}_{3}$ perovskite were synthesized by a standard solution-based two-step procedure. For this purpose, two separate anhydrous solutions were prepared by dissolving lead iodide $\left(\mathrm{PbI}_{2}\right)$ in dimethylformamide(DMF) solvent stirred overnight at $75{ }^{\circ} \mathrm{C}$, and methylammonium iodide 
$\left(\mathrm{CH}_{3} \mathrm{NH}_{3} \mathrm{I}\right)$ in isopropanol stirred at room temperature. In step one, hot $\mathrm{PbI} 2$ solution (450 mg $\mathrm{ml}^{-1}$ ) is spin coated on the HTL and heated at $100{ }^{\circ} \mathrm{C}$ for 10 minutes. Subsequently, in step two, the $\mathrm{CH}_{3} \mathrm{NH}_{3} \mathrm{I}$ solution (45 mg ml${ }^{-1}$ ) was casted on the surface of $\mathrm{PbI}_{2}$, and heated at $100{ }^{\circ} \mathrm{C}$ for additionally 30 minutes. Both steps were conducted inside the nitrogen-filled glove box. The final perovskite film thickness attained was measured to be $350 \pm 50 \mathrm{~nm}$ when PEDOT:PSS is used, and 450 $\pm 50 \mathrm{~nm}$, when PTAA is employed. Before ETL deposition, the samples were once more allowed to cool down to room temperature. For the formation of the ETL, PCBM powder was dissolved in chlorobenzene and stirred for at least $5 \mathrm{~h}$ at $75^{\circ} \mathrm{C}$, with a concentration of 20 $\mathrm{mg} \mathrm{ml}^{-1}$. The PCBM solution was spin coated on the perovskite surface at $1000 \mathrm{rpm}$ for $45 \mathrm{~s}$, and left to dry for $30 \mathrm{~min}$ in a closed petri dish under inert atmosphere. Next, an as-prepared PFN solution of $0.4 \mathrm{mg} \mathrm{ml}^{-1}$ in methanol with a small amount of acetic acid $\left(0.4 \mu \mathrm{ml}^{-1}\right)$ was spin coated at $2000 \mathrm{rpm}$ for $45 \mathrm{~s}$ for the formation of an ultrathin interlayer. Finally, $100 \mathrm{~nm}$ of aluminum was deposited through a shadow mask by thermal evaporation to provide active area electrodes of $4 \mathrm{~mm}^{2}$ for each component device.

\section{Characterization and measurements}

The performances of the fabricated devices were measured under inert atmosphere with an Air Mass 1.5 Global (A. M. $1.5 \mathrm{G}$ ) solar simulator at an intensity of $100 \mathrm{~mW} \mathrm{~cm} \mathrm{~cm}^{-2}$ using an Agilent B1500A Semiconductor Device Analyzer. The external quantum efficiency measurements were conducted immediately after device fabrication at encapsulated PSCs using an integrated system (Enlitech, Taiwan) and a lock-in amplifier with a current preamplifier under short-circuit conditions. The light spectrum was calibrated using a monocrystalline photodetector of known spectral response. The PSCs were measured using a Xe lamp passing through a monochromator 
and an optical chopper at low frequencies $(\approx 200 \mathrm{~Hz})$ in order to maximize the signal/noise $(\mathrm{S} / \mathrm{N})$ ratio.

The crystal structure of the $\mathrm{CH}_{3} \mathrm{NH}_{3} \mathrm{PbI}_{3}$ perovskite was studied by an X-Ray Rigaku (RINT2000) Diffractometer operating with a continuous scan of $\mathrm{Cu}$ Kal radiation with $\lambda=1.54056 \AA$. All XRD measurements were performed with a scan rate of $0.1^{\circ} / \mathrm{s}$ in the range of $2 \theta=5^{\circ}-60^{\circ}$. The transmittance spectra were recorded using a Shimadzu UV-2401 PC spectrophotometer over the wavelength range of $300-800 \mathrm{~nm}$. The topography and roughness of the HTLs were examined by means of atomic force microscopy (AFM), by employing a Park XE-7 instrument in tapping mode. All AFM measurements were performed with a scan rate of $0.3 \mathrm{~Hz}$, while the total area of each scan was $1 \mathrm{x} 1 \mu \mathrm{m}$. A field emission scanning electron microscope (JEOL, JSM$7000 \mathrm{~F}$ ), was used to examine the morphology of the perovskite structures.

Microphotoluminescence ( $\mu \mathrm{PL})$ studies at $295 \mathrm{~K}$ were performed using a setup in backscattering geometry, with an $\mathrm{He}-\mathrm{Ne} 543 \mathrm{~nm}$ continuous wave laser as the excitation source. The laser beam was focused down to $1 \mu \mathrm{m}$ on the sample through an objective lens (Mitutoyo $50 \times$ ), placed on an XYZ translation stage, at normal incidence. A spatial filter system was used to obtain the central part of the beam and acquire a uniform energy distribution. In a typical $\mu \mathrm{PL}$ experiment, different excitation positions of the samples were checked with low laser power controlled by a neutral density filter, in order to verify sample homogeneity.

Transient absorption spectroscopy (TAS) measurements were performed on a Newport (TAS1) transient absorption spectrometer, with a source pulsed laser beam generated from an Yb:KGW-based laser system (PHAROS, Light Conversion), emitting at $1026 \mathrm{~nm}$, with a pulse duration of $170 \mathrm{fs}$ and $1 \mathrm{KHz}$ repetition rate. As shown schematically in Figure S1, the $1026 \mathrm{~nm}$ the source beam is split, so that the probe beam component ( $10 \%$ of the source) passes through a 
delay line and routed on a YAG crystal which generates a white light supercontinuum of 600$900 \mathrm{~nm}$. The other part of the incident beam ( $90 \%$ of the source), is used as pump beam for sample excitation. It should be mentioned that, owing to the photon energy of the laser source used, the excitation of the active layer occurred via a two-photon absorption process. In our case, the sum of the photon energies corresponding to two, $1026 \mathrm{~nm}$, photons (i.e. $\sim 2.42 \mathrm{eV}$ ), exceeds the band gap of $\mathrm{MAPbI}_{3}(\sim 1.6 \mathrm{eV})$. The energy of the pump beam can be controlled by a variable reflective neutral density filter inside the TAS instrument, or by altering the power of the employed $1026 \mathrm{~nm}$ fundamental laser beam. For the present study the former method is preferred, while the sample damage threshold was found to be $1.5 \mathrm{~mJ} \mathrm{~cm}^{-2}$. For all measurements, the probe light is coupled through and optical fiber to a multichannel detector and monitored as a function of wavelength. In a typical TAS pump-probe experiment, the sample is excited by the pump beam and the corresponding decay dynamics of the sample's relative optical density are recorded as a function of wavelength at various time delays after photoexcitation.

\section{Results and Discussion}

\section{Structural and Morphological characterization}

The efficiency of PSCs is always correlated with the proper formation of the hybrid perovskite absorber and differences in the crystal structure, grain size and grain boundaries, of the perovskite could significantly affect the devices performance. ${ }^{9}$ In this way, the structural and morphological characteristics of the $\mathrm{CH}_{3} \mathrm{NH}_{3} \mathrm{PbI}_{3}$ perovskite layer upon its growth on the two different types of HTL polymers (PEDOT:PSS and PTAA) was investigated. In a first step, the change of the crystalline structure of the perovskite film was investigated by XRD. Both XRD profiles are dominated by two main peaks at $14^{\circ}$ and $28.4^{\circ}$, corresponding to the (110) and (220) 
lattice planes of the $\mathrm{CH}_{3} \mathrm{NH}_{3} \mathrm{PbI}_{3}$ perovskite, respectively. ${ }^{22,27,33,41}$ While, the much weaker signatures at $24.4^{\circ}$ and $31.8^{\circ}$ are respectively attributed to the (202) and (310) crystal reflections. It can be concluded that XRD patterns (Figure S2) reveal no obvious changes on the quality of the $\mathrm{CH}_{3} \mathrm{NH}_{3} \mathrm{PbI}_{3}$ perovskite crystal upon using HTL substrates of reduced wettability.

Considering the lack of differences between the XRD patterns of the perovskite films onto PTAA and PEDOT:PSS layers, scanning electron microscopy (SEM) was employed to further shed light on the morphology of the perovskite structure, while atomic force microscopy (AFM) was performed to reveal the nature of the employed HTL surfaces. In particular, Figures 1a-b present the AFM images of PEDOT:PSS and PTAA polymer surfaces, prior to the growth of the perovskite layer, while corresponding analysis reveals average roughness values of 0.942 and $0.580 \mathrm{~nm}$, for the PEDOT:PSS and PTAA surfaces, respectively. Furthermore, Figures 1c-d show SEM photos of the $\mathrm{CH}_{3} \mathrm{NH}_{3} \mathrm{PbI}_{3}$ perovskite grown onto PEDOT:PSS and PTAA layers, respectively. Strikingly enough, it becomes apparent from SEM images inspection, that the perovskite formed on the smoother PTAA layer exhibits considerably larger grains, which are known to favor the electric performance of the PSC device, mainly due to reduced trap assisted recombination, which significantly affects the $\mathrm{V}_{\mathrm{oc}}$ value. ${ }^{2,35}$ Notably, it appears that such differences in the perovskite crystalline morphology were not traceable by means of XRD analysis, in agreement with recent findings of $\mathrm{Bi}$ et al., ${ }^{35}$ where it is also reported the identical XRD patterns for both PEDOT:PSS/CH${ }_{3} \mathrm{NH}_{3} \mathrm{PbI}_{3}$ and PTAA/ $\mathrm{CH}_{3} \mathrm{NH}_{3} \mathrm{PbI}_{3}$ designs, while having dissimilar crystal grains morphology.

Moreover, the contact angles of water on PEDOT:PSS and PTAA polymers synthesized for the needs of the present study following standard synthetic protocols were measured several times and found to be equal to $20^{\circ}$ and $40^{\circ}\left( \pm 1^{\circ}\right)$ respectively (Figure S3), i.e. both well within 
the hydrophilic regime. While the recent report by $\mathrm{Bi}$ et al. attributes the formation of larger perovskite grains on surfaces with reduced wettability and good smoothness, there was no evidence, to date, about which of the two factors plays the more fundamental role on prompting the formation of larger perovskite crystal grains. However, findings of the present study reveal clear evidence that the HTL surface smoothness is indeed the dominant factor for granting a better substrate for the formation of larger and more uniform grains, and thus, for the realization of PSCs with enhanced performances. Thus, it is widely accepted that the HTL surface roughness strongly correlates with the recombination rates, with surfaces of higher roughness exhibiting slower recombination dynamics being the typical behavior. ${ }^{42,43}$

\section{Optical and Electrical characterization of the PSCS}

The most important role of the HTL in PSC, which is illustrated in Figure 2a, is to prevent the recombination at the semiconductor/electrode interface, and in turn to facilitate the hole extraction at the respective electrode of the device. Thus, prior to the fabrication and characterization of PSCs, we studied the PL characteristics of PEDOT:PSS or PTAA $/ \mathrm{CH}_{3} \mathrm{NH}_{3} \mathrm{PbI}_{3}$ in order to have an indication regarding the hole extraction among the two different samples. Figure $2 \mathrm{~b}$ presents the $\mu$-PL spectra of both systems, where one can observe significant quenching $(\sim 20 \%)$ for the PTAA architecture relatively to the PEDOT:PSS one, accompanied with negligible shift of the $\mu \mathrm{PL}$ peak. This finding suggests that upon introducing the smoother and more hydrophobic PTAA polymer, the charge transport dynamics at the HTL/perovskite interface are accelerated, ${ }^{7,32}$ and an enhancement in the device short circuit current $\left(\mathrm{J}_{\mathrm{sc}}\right)$ density is expected. It should be noted that identical $\mu \mathrm{PL}$ spectra were recorded at several spots across the samples surface, suggesting homogeneous PL characteristics. 
Figure 2c presents the current density-voltage $(\mathrm{J}-\mathrm{V})$ curves for the two types of fabricated PSCs, i.e. with PEDOT:PSS and PTAA polymers as HTL. The J-V characteristics plotted for forward and reverse bias scan (Figure S4), indicate the absence of the hysteresis effect for both types of devices tested. The averaged PV characteristics together with the standard deviations, extracted from 24 identical cells for each case, are summarized in Table 1. Surprisingly, and in contradiction to the PL characteristics, the $\mathrm{J}_{\mathrm{sc}}$ of the PTAA based devices was comparable with the $\mathrm{J}_{\mathrm{sc}}$ of the PEDOT:PSS based devices. On the other hand, upon PTAA incorporation, a noteworthy improvement in the $\mathrm{V}_{\mathrm{oc}}$ is observed as it increases from 926 to $1010 \mathrm{mV}$, accompanied by a remarkable enhancement in the fill factor (FF) from $65.5 \%$ to $76.7 \%$. The significant enhancement in the open circuit voltage $\left(\mathrm{V}_{\mathrm{oc}}\right)$ value of PTAA based devices can be directly correlated with the higher formed grains size of the $\mathrm{CH}_{3} \mathrm{NH}_{3} \mathrm{PbI}_{3}$ compared to the lower grains formed when PEDOT:PSS is used as HTL. ${ }^{27}$ However, one cannot exclude the contribution to the observed $\mathrm{V}_{\mathrm{oc}}$ enhancement, attributed to the improved PTAA-perovskite energy alignment, compared to the PEDOT:PSS-perovskite one, as depicted in Figure S5. While, the enhancement in the fill factor (FF) can be directly correlated with the importantly decreased series resistance $\left(R_{s}\right)$ values of the PTAA based devices $(5.83 \Omega \mathrm{cm})$ compared with the PEDOT:PSS based devices $(7.23 \Omega \mathrm{cm})$. A notable improvement of $\mathrm{V}_{\mathrm{oc}}(\sim 9 \%)$ and $\mathrm{FF}(\sim 17 \%)$ leads to a considerable PCE enhancement of $\sim 24 \%$ (Table 1), with final averaged PCEs of 15.67 and $12.60 \%$ for the PTAA and PEDOT:PSS based devices, respectively. The detailed statistics clearly display that the power conversion efficiency for all devices were improved when the PTAA was used as HTL.

Figure $2 \mathrm{~d}$ displays the corresponding external quantum efficiency (EQE) spectra for the PTAA and PEDOT:PSS HTL based devices. In particular, compared to the PEDOT:PSS, the EQE of 
the PTAA HTL is enhanced in the ranges 470 to $600 \mathrm{~nm}$ and 670 to $770 \mathrm{~nm}$, while it is reduced from 300 to $470 \mathrm{~nm}$ and 600 to $670 \mathrm{~nm}$. Notably, the calculated $J_{\mathrm{sc}}$ obtained from the EQE measurements, matches well to the actual measured $\mathrm{J}_{\mathrm{sc}}$ for the two devices (Table 1), indicating the good accuracy of the electrical measurements performed. By carefully comparing the shape of the EQE spectra of the two different based HTL PSCs, we detected an unexpected lower response of the PTAA PSCs at wavelengths below $470 \mathrm{~nm}$, as compared to PEDOT:PSS based devices. The EQE results triggered us to study and compare the transmittance spectra of the PTAA and PEDOT:PSS coated glass/ITO substrates, since it is the only way to explain this important difference at lower wavelengths of the $\mathrm{EQE}$ spectra and could possibly explain the mismatch of the I-V and PL measurements. However, before comparing the transmittance spectra of PTAA and PEDOT:PSS, it is vital to emphasize the practical difference on how the I$\mathrm{V}$ and PL measurements were conducted; on the one hand for the I-V measurements, the solar light passes through the glass/ITO/HTL substrates before reaches the $\mathrm{CH}_{3} \mathrm{NH}_{3} \mathrm{PbI}_{3}$ absorber, while for the PL measurements, the monochromatic light used as excitation source, directly passes through $\mathrm{CH}_{3} \mathrm{NH}_{3} \mathrm{PbI}_{3}$ absorber (without passing through the ITO/HTL substrates). Based on the above, the contradiction between the I-V and PL measurements in the systems studied, is due to an increased parasitic absorption induced in the front surface of the cell upon incorporation of the PTAA instead of PEDOT:PSS HTL, reducing in this way the amount of photons reaching the $\mathrm{CH}_{3} \mathrm{NH}_{3} \mathrm{PbI}_{3}$ absorber, that is present only for the $\mathrm{I}-\mathrm{V}$ measurements. In this way, we measured and presented the comparison between the transmittance spectra of ITO/PTAA or ITO/PEDOT:PSS substrates. As it can be easily observed in Figure S6, by using the PTAA hole transporter the transmission of the light is significantly decreased if compared with the PEDOT:PSS hole transporter. Taking this into account, the introduction of PTAA as the 
HTL indeed increases the parasitic absorption of the front surface, the $J_{\mathrm{sc}}$ of the respective devices could be significantly higher if PTAA and PEDOT:PSS polymers exhibited similar transparency, i.e. which is indeed not the case (see Figure S6).

\section{Transient absorption spectroscopy (TAS) studies}

In order to identify the origins of the enhanced performance upon using PTAA instead of PEDOT:PSS as HTL, the carrier transport dynamics of the PEDOT:PSS/ $\mathrm{CH}_{3} \mathrm{NH}_{3} \mathrm{PbI}_{3}$ and PTAA/ $\mathrm{CH}_{3} \mathrm{NH}_{3} \mathrm{PbI}_{3}$ systems were thoroughly investigated by TAS and correlated with the photovoltaic characteristics, i.e. $\mathrm{J}_{\mathrm{sc}}, \mathrm{V}_{\mathrm{oc}}$ and FF. The TAS technique is considered to be a powerful tool for extracting information regarding charge carrier transfer, recombination dynamics and relaxation times in PSCs. ${ }^{733,36-39,44-48}$ However most of TAS studies reported to date have been performed in ambient air conditions. On the contrary, all TAS measurements we report here were performed using a specially designed homemade cell (depicted in Figure S1), enabling us to maintain inert atmospheric conditions throughout the whole measurement duration, i.e. $30 \mathrm{~min}$. Thus, the humidity degradation effects and oxygen contamination of the perovskite layer are excluded in the present study.

Figure 3 displays typical 3D graphs of the relative optical density $(\Delta \mathrm{OD})$ as a function of wavelength and time for the two systems studied, as well as typical $\Delta \mathrm{OD}$ versus wavelength plots at various time delays, following photo-excitation at $1026 \mathrm{~nm}$ with a pump fluence of 1.5 $\mathrm{mJ} \mathrm{cm}{ }^{-2}$. The main $\Delta \mathrm{OD}$ peak at $\sim 750 \mathrm{~nm}$, while a photo-induced transient absorption (TA) in the range of $600-700 \mathrm{~nm}$ is also observed and found to attenuate with time. ${ }^{8,34}$ It should be noted here that a linear dependence of $\Delta \mathrm{OD}$ against pump fluence was observed and depicted in Figure S7. 
The relaxation dynamics of the transient photo-induced bleaching, measured at various excitation fluencies, as well as the corresponding decay kinetics were thoroughly investigated following both exponential and polynomial fitting analysis. The first fitting approach allows us to determine critical time components of the charge carrier transport processes between the perovskite film and the employed hole transport layers, ${ }^{33,48}$ i.e. PEDOT:PSS and PTAA, while the higher-order polynomial model provides important kinetic rates for charge carrier recombination processes occurring within the perovskite film. ${ }^{36,37,44-47}$ Figure 4 presents threeexponential fittings based on the equation $\mathrm{y}=\mathrm{y}_{0}+\mathrm{A}_{1} \exp \left(-\mathrm{x} / \tau_{1}\right)+\mathrm{A}_{2} \exp \left(-\mathrm{x} / \tau_{2}\right)+\mathrm{A}_{3} \exp \left(-\mathrm{x} / \tau_{3}\right)$ for all pump fluences studied. All kinetic fit parameters, obtained for the two architectures, are summarized in Table 2. In particular, the fast time component $\left(\tau_{1}\right)$ is attributed to charge carrier trapping at perovskite grain boundaries and perovskite/HTL interfaces. ${ }^{33}$ This component is observed even at the lowest pump fluence, however, for that fluence $\tau_{1}$ is too slow and comparable to $\tau_{2}$; this possibly indicates a difference in the decay kinetics at the lowest fluence, compared to higher fluences (i.e two-versus three-exponential kinetic model respectively). However, regardless the pump fluence employed, i.e. $0.8,1.3$ and $1.5 \mathrm{~mJ} \mathrm{~cm}^{-2}$, the respective time decay components, $\tau_{1}$, are found to be significantly faster for the PTAA architecture, i.e. 218, 22 and 10 ps compared to 305,57 and 43 ps, respectively. This time component represents the time that an excited electron needs to move from the conduction band to the trap states. Thus, smaller $\tau_{1}$ times suggest quicker traps filling, that leads to larger splitting in the quasi-Fermi energy levels that account plausibly for the observed enhanced $V_{o c}$ of the PTAA devices (Table 1). In the meantime, free charge carriers are injected more easily to the HTL, leading to enhanced FF and PCE. ${ }^{49,50}$ Notably, this time component is not solely affected by the density of trap states, but it also depends on the trap states depth. ${ }^{51}$ 
In addition, the second component $\left(\tau_{2}\right)$ is assigned to the hole injections from the perovskite into HTL. ${ }^{33,48}$ As is the case for $\tau_{1}$, inspection of data in Table 2 reveals considerably quicker $\tau_{2}$ decay components also when the PTAA is employed as HTL for all studied fluencies, suggesting faster hole transport dynamics. Indicatively, for the highest pump fluence, $\tau_{2}$ drops from 257 to 101 ps when PEDOT:PSS is replaced with PTAA. The faster $\tau_{2}$ decay is in agreement with the obtained PL characteristics, in which significant quenching upon addition of PTAA as the HTL indicates a faster hole extraction. Regarding the electrical performance of the devices in question, the as determined faster hole injection dynamics of the PTAA device, result to better electrical characteristics (Table 1). ${ }^{48,52}$ Nevertheless, as explained earlier, while $\mathrm{V}_{\mathrm{oc}}$, FF, and PCE of the PTAA solar cell improve considerably, a comparable $\mathrm{J}_{\mathrm{sc}}$ is found due to the lower transmittance of the PTAA film compared to the PEDOT:PSS, that appears to compensate the faster hole dynamics, i.e. suppressing the $\mathrm{J}_{\mathrm{sc}}$ for further improvement. Despite the comparable $\mathrm{J}_{\mathrm{sc}}$, the obtained $\mathrm{V}_{\mathrm{oc}}, \mathrm{FF}$, and PCE of the PTAA device, $\tau_{2}$ component plays a dominant role on the electrical performance of the device, due to the faster hole injection. Moreover, the revealed $\tau_{2}$ faster decay component complies well with the higher HOMO level of the PTAA polymer, compared to the PEDOT:PSS, as shown in the corresponding energy level diagram depicted in Figure $55 .^{12,13}$

Finally, Table 2 lists the third long-life time component $\left(\tau_{3}\right)$, which is representative of the exciton recombination time. ${ }^{33,48}$ Likewise $\tau_{1}$ and $\tau_{2}$ components, $\tau_{3}$ is also found to be significantly faster for the PTAA architecture at all pump fluences. Remarkably, for the highest employed pump fluence, $\tau_{3}$ reduces from $120 \mathrm{~ns}$ to 717 ps when PTAA is used instead of PEDOT:PSS. In general, the primary recombination processes taking place in perovskite solar cells are as follows. Following photo-excitation, the faster recombination process that occurs, is 
the exciton recombination with typical lifetime values in the order of $10 \mathrm{ps}-10 \mathrm{~ns} .{ }^{53} \mathrm{~A}$ slower recombination mechanism is the recombination at the grain boundaries that occurs in the ns time scale. ${ }^{53,54}$ This study cannot provide information on the trap-assisted recombination processes (i.e. at grain boundaries and interfaces), since these mechanisms lie out of the delay range employed. This is not the case for the exciton (electron-hole) recombination kinetics, represented by $\tau_{3}$ in our experiments. This characteristic time is faster in the case of PTAA-based perovskite system compared to the PEDOT:PSS-based one, indicating the superiority of the former. It should be mentioned here though, that the efficient charge transfer from the perovskite to PTAA will benefit the solar cell efficiency, provided also that the back-electron transfer is much slower. ${ }^{55}$ Furthermore, we consider that the changes observed in time constants due to the different fluences are the result of more photons per pulse per $\mathrm{cm}^{2}$ excited. By increasing the pump fluence, the higher initial carrier density results in more efficient exciton formation ${ }^{56}$ and the excess energy probably leads to faster exciton dissociation ${ }^{57}$. The result of faster exciton dissociation is the mechanisms that have already mentioned in the manuscript in exponential fitting model to occur faster.

Following this exponential fitting approach, we employ another well-established polynomial fitting model based on the following rate equation: $d n(t) / d t=-k_{3} n^{3}-k_{2} n^{2}-k_{1} n$, where $n$ is the charge carrier density and $\mathrm{k}_{1}, \mathrm{k}_{2}$ and $\mathrm{k}_{3}$ the rate constants corresponding respectively to, trapassisted recombination, bimolecular recombination, and Auger tri-molecular recombination processes (Figure S8). ${ }^{36,44-47}$ On a recent report, Wehrenfenning et al. ${ }^{36}$ related the rate of bimolecular recombination $\left(\mathrm{k}_{2}\right)$ with the PCE of PSC devices. Namely, it was proposed that slower $\mathrm{k}_{2}$ rates, are indicative of larger free charge carriers diffusion lengths that favor the performance of planar-heterojunction devices. Table 3 presents the kinetic rate constants as 
determined for the two architectures in question. Inspection of Table 3, reveals that for all studied pump fluencies, the PTAA polymer architecture exhibits slower $\mathrm{k}_{2}$ rates when compared to the corresponding of PEDOT:PSS. Such findings provide additional explanation for the enhanced photovoltaic performance (Table 1) of the former device.

In summary, the exponential fitting approach depicted faster hole injection for the PTAA/perovskite architecture, while the higher order polynomial fitting model revealed slower kinetic rates for the charge carrier recombination processes within the perovskite. Both findings are in agreement and account plausibly for the advanced performance of the PTAA polymer solar cell device.

\section{Conclusions}

Planar inverted $\mathrm{CH}_{3} \mathrm{NH}_{3} \mathrm{PbI}_{3}$ perovskite solar cells were fabricated by a standard solutionbased two-step procedure, while adopting two different types of device architecture. In the first, the super hydrophilic PEDOT:PSS polymer was used as HTL, whereas in the second a more hydrophobic polymer, PTAA, was employed, while keeping all the remaining device components identical. It was found that the introduction of PTAA enhances considerably the performance of the photovoltaic devices. Aiming to investigate the origins of this efficiency enhancement towards the design of novel PSC architectures, transient absorption spectroscopy (TAS) was performed on the HTL/perovskite configurations under inert atmosphere conditions. Analysis of TAS data revealed considerably quicker dynamics and slower bimolecular recombination rates when PTAA polymer is used, that account plausibly for the improved PCEs of the devices in which it was incorporated. Furthermore, experiments clarified that the PCE enhancement is mostly attributed to the reduced roughness of the HTL surface, while a small 
fraction can be ascribed to HTL wettability. Findings of the present work pave the way towards a better understanding of how the surface roughness and wettability of the HTL polymer affects the device performance, while ongoing work focuses on discovering ways for further improvement of the stability and performance of PSCs with HTL materials of reduced hydrophilicity and smoother surfaces.

\section{ASSOSIATED CONTENT}

\section{Supporting Information}

Experimental details, TAS setup, characterization of materials (XRD patterns, contact angle and transmittance spectroscopy of HTLs), dependence of $\Delta \mathrm{OD}$ from pump fluence, transient band edge bleach kinetics and their corresponding decay polynomial fits (lines) and materials energy levels.

\section{AUTHOR INFORMATION}

\section{Corresponding Authors}

*+30 2810-391835. E-mail: ikonid@iesl.forth.gr

*+30 2810-391274. E-mail: stratak@iesl.forth.gr

*+30 2810-379895. E-mail: kymakis@ staff.teicrete.gr

\section{Notes}

The authors declare no competing financial interest. 


\section{ACKNOWLEDGMENT}

This work is supported by the European Research Infrastructure NFFA-Europe, funded by EU's H2020 framework program for research and innovation under grant agreement n. 654360. The authors are grateful to A. Manousaki, E. Gagaoudakis, and I. Paradisanos (all in IESL, FORTH), and M. Krassas (TEI) for their technical assistance with SEM, XRD, $\mu$ PL, and AFM studies respectively.

\section{REFERENCES}

(1) Stranks, S. D.; Snaith, H. J. Metal-Halide Perovskites for Photovoltaic and Light-Emitting Devices. Nat. Nanotechnol. 2015, 10, 391-402.

(2) Lee, Y.; Kwon, J.; Hwang, E.; Ra, C. H.; Yoo, W. J.; Ahn, J. H.; Park, J. H.; Cho, J. H. High-Performance Perovskite-Graphene Hybrid Photodetector. Adv. Mater. 2015, 27, 41-46.

(3) Fang, Y.; Dong, Q.; Shao, Y.; Yuan, Y.; Huang, J. Highly Narrowband Perovskite SingleCrystal Photodetectors Enabled by Surface-Charge Recombination. Nat. Photonics 2015, 9, 679-686.

(4) Xing, G.; Mathews, N.; Lim, S. S., Yantara, N.; Liu, X.; Sabba, D.; Gratzel, M.;

Mhaisalkar, S.; Sum, T. C. Low-Temperature Solution-Processed Wavelength-Tunable Perovskites for Lasing. Nat. Mater. 2014, 13, 476-480.

(5) Tan, Z. K.; Moghaddam, R.S.; Lai, M.L.; Docampo, P.; Higler, R.; Deschler, F.; Price, M.; Sadhanala, A.; Pazos, L. M.; Credgington, D.; Hanusch, F.; Bein, T.; Snaith, H. J.; Friend, R. H. 
Bright Light-Emitting Diodes Based on Organometal Halide Perovskite. Nat. Nanotechnol. 2014, 9, 687-692.

(6) Kumawat, N. K.; Tripathi, M. N.; Waghmare, U. V.; Kabra, D. Structural, Optical and Electronic Properties of Wide Bandgap Perovskites: Experimental \& Theoretical Investigation. $J$. Phys. Chem. A 2016, 120, 3917-3923.

(7) Stranks, S. D.; Eperon, G. E.; Grancini, G.; Menelaou, C.; Alcocer, M. J.; Leijtens, T.; Herz, L. M.; Petrozza, A.; Snaith, H. J. Electron-Hole Diffusion Lengths Exceeding 1 micrometer in an Organometal Trihalide Perovskite Absorber. Science 2013, 342, 341-344.

(8) Lee, Y. H.; Luo, J.; Humphry-Baker, R.; Gao, P.; Grätzel, M.; Nazeeruddin, M. K. Unraveling the Reasons for Efficiency Loss in Perovskite Solar Cells. Adv. Funct. Mater. 2015, $25,3925-3933$.

(9) Song, T. B.; Chen, Q.; Zhou, H.; Jiang, C.; Wang, H. H.; Yang, Y. M.; Yang, Y. Perovskite Solar Cells: Film Formation and Properties. J. Mater. Chem. A 2015, 3, 9032-9050.

(10) Kojima, A.; Teshima, K.; Shirai, Y.; Miyasaka, T. Organometal Halide Perovskites as Visible-Light Sensitizers for Photovoltaic Cells. J. Am. Chem. Soc. 2009, 131, 6050-6051.

(11) Snaith, H. J. Perovskites: The Emergence of a New Era for Low-Cost, High-Efficiency Solar Cells. J. Phys. Chem. Lett. 2013, 4, 3623-3630.

(12) Gao, P.; Grätzel, M.; Nazeeruddin, M. K. Organohalide Lead Perovskites for Photovoltaic Applications. Energy Environ. Sci. 2014, 7, 2448-2463.

(13) NREL Best Research-Cell Photovoltaic Efficiency Chart. 
(14) Agresti, A.; Pescetelli, S.; Palma, A. L.; Del Rio Castillo, A. E.; Konios, D.; Kakavelakis, G.; Razza, S.; Cinà, L.; Kymakis, E.; Bonaccorso, F.; Di Carlo, A. Graphene Interface Engineering for Perovskite Solar Modules: 12.6\% Power Conversion Efficiency over $50 \mathrm{~cm}^{2}$ Active Area. ACS Energy Lett. 2017, 2, 279-289.

(15) Leguy, A. M.; Hu, Y.; Campoy-Quiles, M.; Alonso, M. I.; Weber, O. J.; Azarhoosh, P.; van Schilfgaarde, M.; Weller, M.T.; Bein, T.; Nelson, J.; Docampo, P.; Barnes, P. R. F. Reversible Hydration of $\mathrm{CH}_{3} \mathrm{NH}_{3} \mathrm{PbI}_{3}$ in Films, Single Crystals, and Solar Cells. Chem. Mater. 2015, 27, 3397-3407.

(16) Docampo, P.; Bein, T. A Long-Term View on Perovskite Optoelectronics. Acc. Chem. Res. 2016, 49, 339-346.

(17) Docampo, P.; Ball, J. M.; Darwich, M.; Eperon, G. E.; Snaith, H. J. Efficient Organometal Trihalide Perovskite Planar-Heterojunction Solar Cells on Flexible Polymer Substrates. Nat. Commun. 2013, 4, 2761.

(18) Zhao, C.; Chen, B.; Qiao, X.; Luan, L.; Lu, K.; Hu, B. Revealing Underlying Processes Involved in Light Soaking Effects and Hysteresis Phenomena in Perovskite Solar Cells. Adv. Energy Mater. 2015, 5, 1500279.

(19) Zhao, Y.; Zhu, K. $\mathrm{CH}_{3} \mathrm{NH}_{3} \mathrm{Cl}$-assisted One-Step Solution Growth of $\mathrm{CH}_{3} \mathrm{NH}_{3} \mathrm{PbI}_{3}$ : Structure, Charge-Carrier Dynamics, and Photovoltaic Properties of Perovskite Solar Cells. $J$. Phys. Chem. C 2014, 118, 9412-9418.

(20) Pathak, S.; Sepe, A.; Sadhanala, A.; Deschler, F.; Haghighirad, A.; Sakai, N.; Goedel, K. C.; Stranks, S. D.; Noel, N.; Price, M.; Huttner, S.; Hawkins, N. A.; Friend, R. H.; Steiner, U.; 
Snaith, H. J. Atmospheric Influence upon Crystallization and Electronic Disorder and Its Impact on the Photophysical Properties of Organic-Inorganic Perovskite Solar Cells. ACS Nano 2015, 9 , 2311-2320.

(21) Bi, D.; Tress, W.; Dar, M. I.; Gao, P.; Luo, J.; Renevier, C.; Schenk, K.; Abate, A.; Giordano, F.; Baena, J. B. C.; Decoppet, J. D; Zakeeruddin, S. M.; Nazeeruddin, M. K.; Gratzel, M.; Hagfeldt, A. Efficient Luminescent Solar Cells Based on Tailored Mixed-Cation Perovskites. Sci. Adv. 2016, 2, e1501170.

(22) Li, F.; Zhu, W.; Bao, C.; Yu, T.; Wang, Y.; Zhou, X.; Zou, Z. Laser-Assisted Crystallization of $\mathrm{CH}_{3} \mathrm{NH}_{3} \mathrm{PbI}_{3}$ Films for Efficient Perovskite Solar Cells with a High OpenCircuit Voltage. Chem. Commun. 2016, 52, 5394-5397.

(23) Jeon, T.; Jin, H. M.; Lee, S. H.; Lee, J. M.; Park, H. I.; Kim, M. K.; Lee, J. K.; Shin, B.; Kim, S. O. Laser Crystallization of Organic-Inorganic Hybrid Perovskite Solar Cells. ACS Nano 2016, 10, 7907-7914.

(24) Burschka, J.; Pellet, N.; Moon, S. J.; Humphry-Baker, R.; Gao, P.; Nazeeruddin, M. K.; Grätzel, M. Sequential Deposition as a Route to High-Performance Perovskite-Sensitized Solar Cells. Nature 2013, 499, 316-319.

(25) Somsongkul, V.; Lang, F.; Jeong, A. R.; Rusu, M.; Arunchaiya, M.; Dittrich, T. Hole Blocking $\mathrm{PbI}_{2} / \mathrm{CH}_{3} \mathrm{NH}_{3} \mathrm{PbI}_{3}$ Interface. Phys. Status Solidi RRL. 2014, 8, 763-766.

(26) Liu, M.; Johnston, M. B.; Snaith, H. J. Efficient Planar Heterojunction Perovskite Solar Cells by Vapour Deposition. Nature 2013, 501, 395-398. 
(27) Chen, Q.; Zhou, H.; Hong, Z.; Luo, S.; Duan, H. S.; Wang, H. H.; Liu, Y.; Li, G.; Yang, Y. Planar Heterojunction Perovskite Solar Cells via Vapor-Assisted Solution Process. J. Am. Chem. Soc. 2013, 136, 622-625.

(28) Xiao, Z.; Dong, Q.; Bi, C.; Shao, Y.; Yuan, Y.; Huang, J. Solvent Annealing of Perovskite-Induced Crystal Growth for Photovoltaic-Device Efficiency Enhancement. Adv. Mater. 2014, 26, 6503-6509.

(29) Nie, W.; Blancon, J. C.; Neukirch, A. J.; Appavoo, K.; Tsai, H.; Chhowalla, M.; Alam, M. A; Sfeir, M. Y.; Katan, C.; Even, J.; Tretiak, S.; Crochet, J. J.; Gupta, G.; Mohite, A. D. LightActivated Photocurrent Degradation and Self-Healing in Perovskite Solar Cells. Nature Commun. 2016, 7, 11574.

(30) Domanski, K.; Roose, B.; Matsui, T.; Saliba, M.; Turren-Cruz, S. H.; Correa-Baena, J. P.; Carmona, C. R.; Richardson, G.; Jamie, M.; Foster, J.M.; De Angelis, F.; Ball, J. M.; Petrozza, A.; Mine, N.; Nazeeruddin, M. K.; Tress, W.; Gratzel, M.; Steiner, U.; Hagfeldt, A.; Abate, A. Migration of Cations Induces Reversible Performance Losses over Day/Night Cycling in Perovskite Solar Cells. Energy Environ. Sci. 2017, DOI: 10.1039/C6EE03352K.

(31) Wang, Q.; Bi, C.; Huang, J. Doped Hole Transport layer for Efficiency Enhancement in Planar Heterojunction Organolead Trihalide Perovskite Solar Cells. Nano Energy 2015, 15, 275280.

(32) Kakavelakis, G.; Maksudov, T.; Konios, D.; Paradisanos, I.; Kioseoglou, G.; Stratakis, E.; Kymakis, E. Efficient and Highly Air Stable Planar Inverted Perovskite Solar Cells with 
Reduced Graphene Oxide Doped PCBM Electron Transporting Layer. Adv. Energy Mater. 2016, DOI: $10.1002 /$ aenm.201602120

(33) Wang, L.; McCleese, C.; Kovalsky, A.; Zhao, Y.; Burda, C. Femtosecond Time-Resolved Transient Absorption Spectroscopy of $\mathrm{CH}_{3} \mathrm{NH}_{3} \mathrm{PbI}_{3}$ Perovskite Films: Evidence for Passivation Effect of $\mathrm{PbI}_{2} . J$. Am. Chem. Soc. 2014, 136, 12205-12208.

(34) Heo, J. H.; Han, H. J.; Kim, D.; Ahn, T. K.; Im, S. H. Hysteresis-Less Inverted $\mathrm{CH}_{3} \mathrm{NH}_{3} \mathrm{PbI}_{3}$ Planar Perovskite Hybrid Solar Cells with $18.1 \%$ Power Conversion Efficiency. Energy Environ. Sci. 2015, 8, 1602-1608.

(35) Bi, C.; Wang, Q.; Shao, Y.; Yuan, Y.; Xiao, Z.; Huang, J. Non-Wetting Surface-Driven High-Aspect-Ratio Crystalline Grain Growth for Efficient Hybrid Perovskite Solar Cells. Nat. Commun. 2015, 6, 7747.

(36) Wehrenfennig, C.; Eperon, G. E.; Johnston, M. B.; Snaith, H. J.; Herz, L. M. High Charge Carrier Mobilities and Lifetimes in Organolead Trihalide Perovskites. Adv. Mater. 2014, 26, $1584-1589$.

(37) Piatkowski, P.; Cohen, B.; Ramos, F. J.; Di Nunzio, M.; Nazeeruddin, M. K.; Grätzel, M.; Ahmad, S.; Douhal, A. Direct Monitoring of Ultrafast Electron and Hole Dynamics in Perovskite Solar Cells. Phys. Chem. Chem. Phys. 2015, 17, 14674-14684.

(38) Ishioka, K.; Barker, B. G.; Yanagida, M.; Shirai, Y.; Miyano, K. Direct Observation of Ultrafast Hole Injection from Lead Halide Perovskite by Differential Transient Transmission Spectroscopy. J. Phys. Chem. Lett. 2017, 8, 3902-3907. 
(39) Corani, A.; Li, M. H.; Shen, P. S.; Chen, P.; Guo, T. F.; El Nahhas, A.; Zheng, K.; Yartsev, A.; Sundstrom, V.; Ponseca Jr, C. S. Ultrafast Dynamics of Hole Injection and Recombination in Organometal Halide Perovskite Using Nickel Oxide as p-Type Contact Electrode. J. Phys. Chem. Lett 2016, 7, 1096-1101.

(40) Chen, Q.; Zhou, H.; Song, T. B.; Luo, S.; Hong, Z.; Duan, H. S.; Dou, L.; Liu, Y. Yang, Y. Controllable Self-Induced Passivation of Hybrid Lead Iodide Perovskites Toward High Performance Solar Cells. Nano Lett. 2014, 14, 4158-4163.

(41) Huang, J. H.; Jiang, K. J.; Cui, X. P.; Zhang, Q. Q.; Gao, M.; Su, M. J.; Song, Y. Direct Conversion of $\mathrm{CH}_{3} \mathrm{NH}_{3} \mathrm{PbI}_{3}$ from Electrodeposited $\mathrm{PbO}$ for Highly Efficient Planar Perovskite Solar Cells. Sci. Rep. 2015, 5, 15889.

(42) McEvoy, A., Markvart, T., Castañer, L. Practical Handbook of Photovoltaics: Fundamentals and Applications. Elsevier, 2003.

(43) McEvoy, A. J., Castaner, L., Markvart, T. Solar cells: Materials, Manufacture and Operation. Academic Press, 2012.

(44) Stranks, S. D.; Burlakov, V. M.; Leijtens, T.; Ball, J. M.; Goriely, A.; Snaith, H. J. Recombination Kinetics in Organic-Inorganic Perovskites: Excitons, Free Charge, and Subgap States. Phys.Rev. Appl. 2014, 2, 034007.

(45) Manser, J. S.; Kamat, P. V. Band Filling with Free Charge Carriers in Organometal Halide Perovskites. Nat. Photonics 2014 8, 737-743.

(46) La-o-vorakiat, C.; Salim, T.; Kadro, J.; Khuc, M. T.; Haselsberger, R.; Cheng, L.; Xia, H.; Gurzadyan, G. G.; Su, H.; Lam, Y. M.; Marcus, R. A.; Michel-Beyerle, M. E.; Chia, E. E. M. 
Elucidating the Role of Disorder and Free-Carrier Recombination Kinetics in $\mathrm{CH} 3 \mathrm{NH} 3 \mathrm{PbI} 3$ Perovskite Films. Nat. Commun. 2015, 7, DOI:10.1038/ncomms8903.

(47) Klein, J. R.; Flender, O.; Scholz, M.; Oum, K.; Lenzer, T. Charge Carrier Dynamics of Methylammonium Lead Iodide: from $\mathrm{PbI}$ 2-rich to Low-Dimensional Broadly Emitting Perovskites. Phys. Chem. Chem. Phys. 2016, 18, 10800-10808.

(48) Zhu, Z.; Ma, J.; Wang, Z.; Mu, C.; Fan, Z.; Du, L.; Yang B.; Fan L.; Yan H.; Phillips D. L.; Yang, S. Efficiency Enhancement of Perovskite Solar Cells Through Fast Electron Extraction: the Role of Graphene Quantum Dots. J. Am. Chem. Soc. 2014, 136, 3760-3763.

(49) Shao, S.; Abdu-Aguye, M.; Sherkar, T. S.; Fang, H. H.; Adjokatse, S.; Brink, G. T.; Kooi, B. J.; Koster, L. J. A.; Loi, M. A. The Effect of the Microstructure on Trap-Assisted Recombination and Light Soaking Phenomenon in Hybrid Perovskite Solar Cells. Adv. Funct. Mater. 2016, 26, 8094-8102.

(50) Leijtens, T.; Stranks, S. D.; Eperon, G. E.; Lindblad, R.; Johansson, E. M.; McPherson, I. J.; Rensmo, H.; Ball, J. M.; Lee, M. M.; Snaith, H. J. Electronic Properties of MesoSuperstructured and Planar Organometal Halide Perovskite Films: Charge Trapping, Photodoping, and Carrier Mobility. ACS Nano 2014, 8, 7147-7155.

(51) Leijtens, T.; Eperon, G. E.; Barker, A. J.; Grancini, G.; Zhang, W.; Ball, J. M.; Kandada, A. R. S.; Snaith H. J.; Petrozza, A. Carrier Trapping and Recombination: The Role of Defect Physics in Enhancing the Open Circuit Voltage of Metal Halide Perovskite Solar Cells. Energy Environ. Sci. 2016, 9, 3472-3481. 
(52) Tao, C.; Neutzner, S.; Colella, L.; Marras, S.; Kandada, A. R. S.; Gandini, M.; De Bastiani M.; Pace G.; Manna L.; Caironi, M.; Bertarelli, C.; Petrozza, A. 17.6\% Stabilized Efficiency in Low-Temperature Processed Planar Perovskite Solar Cells. Energy Environ. Sci. 2015, 8, 23652370 .

(53) Bernardi, M.; Grossman, J. C. Computer Calculations Across Time and Length Scales in Photovoltaic Solar Cells Energy Environ. Sci. 2016, 9, 2197-2218.

(54) Metzger, W. K. How Lifetime Fluctuations, Grain-Boundary Recombination, and Junctions Affect Lifetime Measurements and their Correlation to Silicon Solar Cell Performance. Sol. Energy Mater. Sol. Cells 2008, 92, 1123-1135.

(55) Marchioro, A.; Teuscher, J.; Friedrich, D.; Kunst, M.; Van De Krol, R.; Moehl, T.; Gratzel, M.; Moser, J. E. Unravelling the Mechanism of Photoinduced Charge Transfer Processes in Lead Iodide Perovskite Solar Cells. Nat. Photonics. 2014, 8, 250-255.

(56) Piatkowski, P.; Cohen, B.; Kazim, S.; Ahmad, S.; Douhal, A. How Photon Pump Fluence Changes the Charge Carrier Relaxation Mechanism in an Organic-Inorganic Hybrid Lead Triiodide Perovskite. Phys. Chem. Chem. Phys. 2016, 18, 27090-27101

(57) Piatkowski, P.; Cohen, B.; Ponseca Jr, C. S.; Salado, M.; Kazim, S.; Ahmad, S.; Sundstrom, V.; Douhal, A. Unraveling Charge Carriers Generation, Diffusion, and Recombination in Formamidinium Lead Triiodide Perovskite Polycrystalline Thin Film. J. Phys. Chem. Lett. 2016, 7, 204-210. 


\section{Figures and Tables:}

$$
\text { (a) }
$$

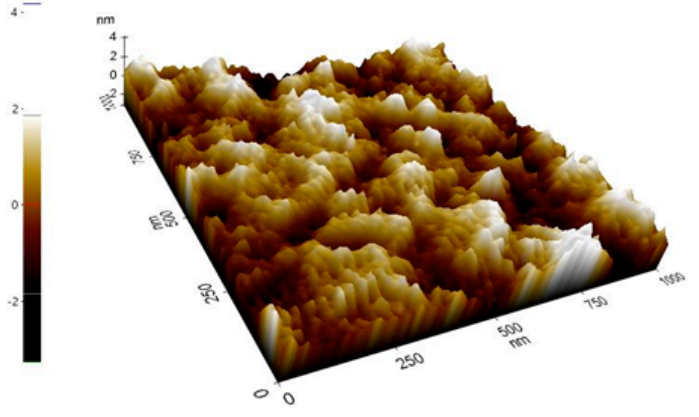

(c)

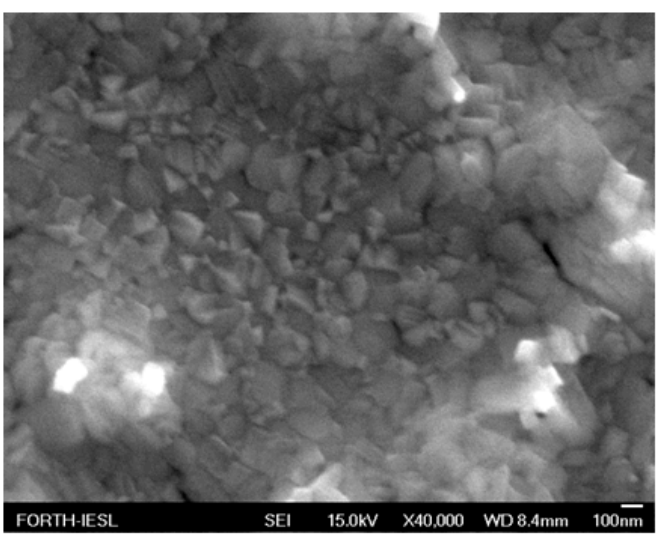

(b)

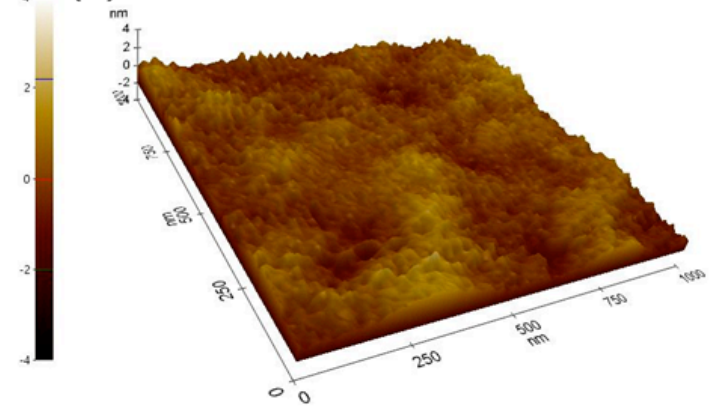

(d)

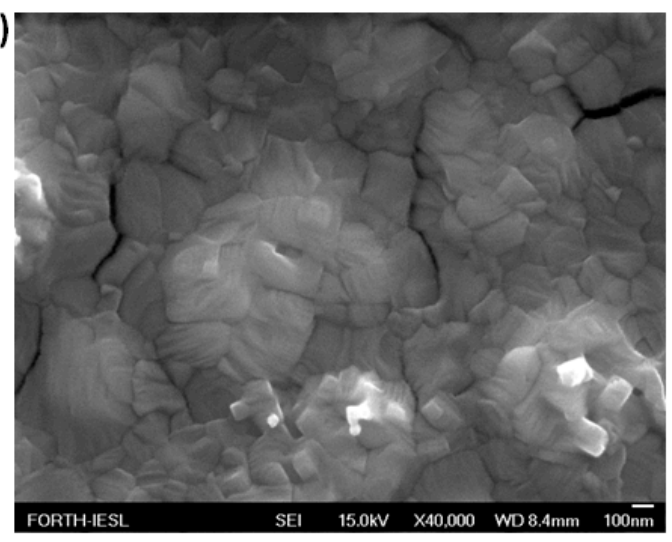

Figure 1. Atomic force microscopy (AFM) surface profiles of PEDOT:PSS (a) and PTAA (b) polymers prior to $\mathrm{CH}_{3} \mathrm{NH}_{3} \mathrm{PbI}_{3}$ perovskite deposition. Scanning electron microscopy (SEM) photos of the $\mathrm{CH}_{3} \mathrm{NH}_{3} \mathrm{PbI}_{3}$ perovskite structure grown on PEDOT:PSS (c) and PTAA (d) hole transport layers. 
(a)
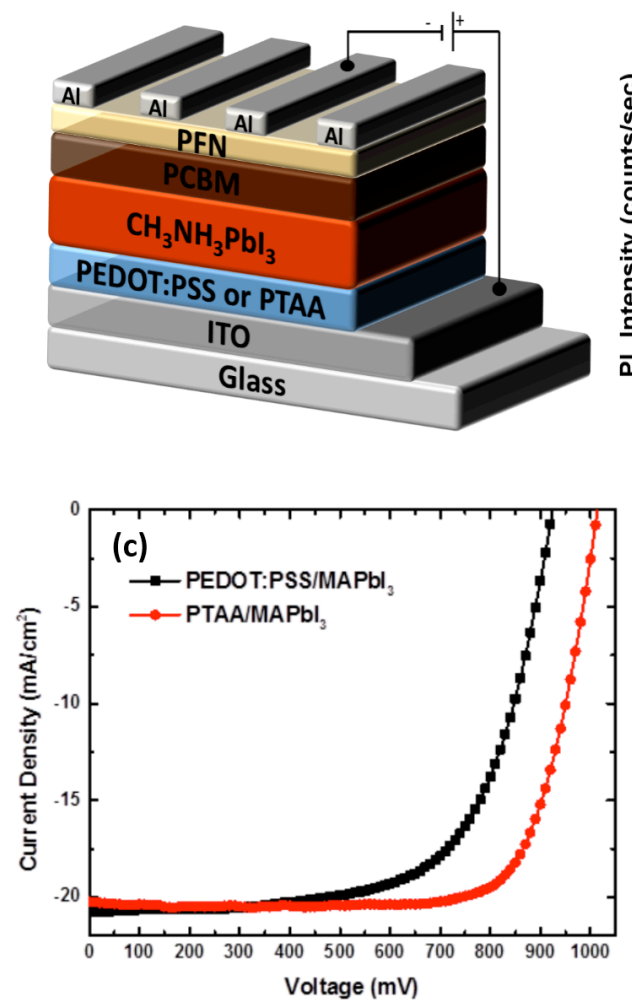

(b)
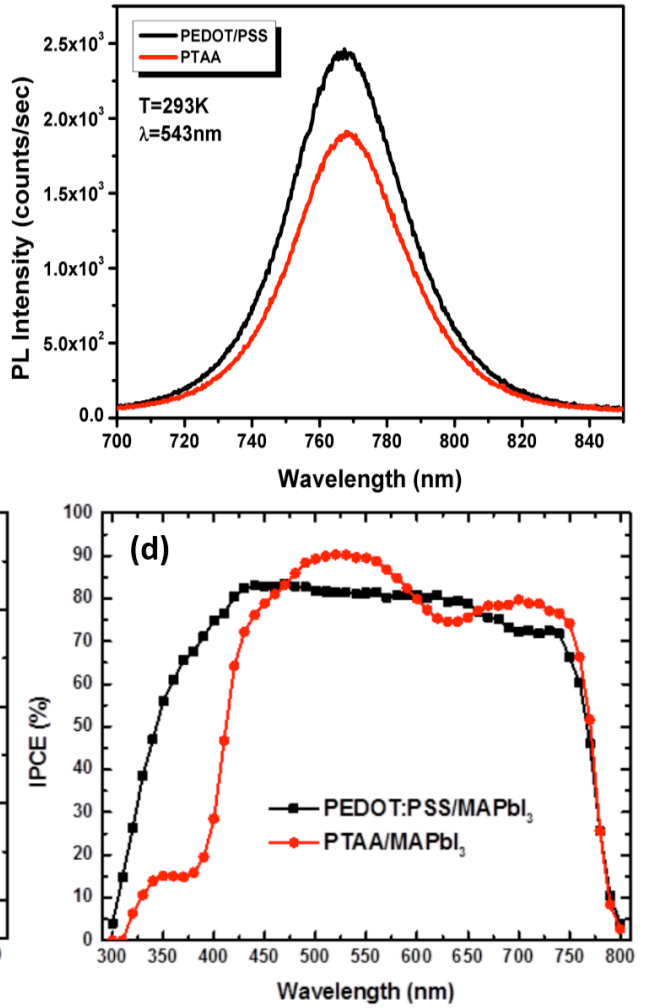

Figure 2. (a) Device architecture of the fabricated planar inverted perovskite solar cells (PSCs). (b) Microphotoluminescence $(\mu \mathrm{PL})$ spectra following excitation at $543 \mathrm{~nm}$ of PEDOT:PSS/ $\mathrm{CH}_{3} \mathrm{NH}_{3} \mathrm{PbI}_{3}$ and PTAA/ $\mathrm{CH}_{3} \mathrm{NH}_{3} \mathrm{PbI}_{3}$ architectures. (c) Current density-voltage (JV)curves of PSCs measured under A. M. $1.5 \mathrm{G}\left(100 \mathrm{~mW} \mathrm{~cm} \mathrm{~cm}^{-2}\right)$ illumination, and (d) corresponding external quantum efficiency (EQE) spectra. 
(a)

(b)
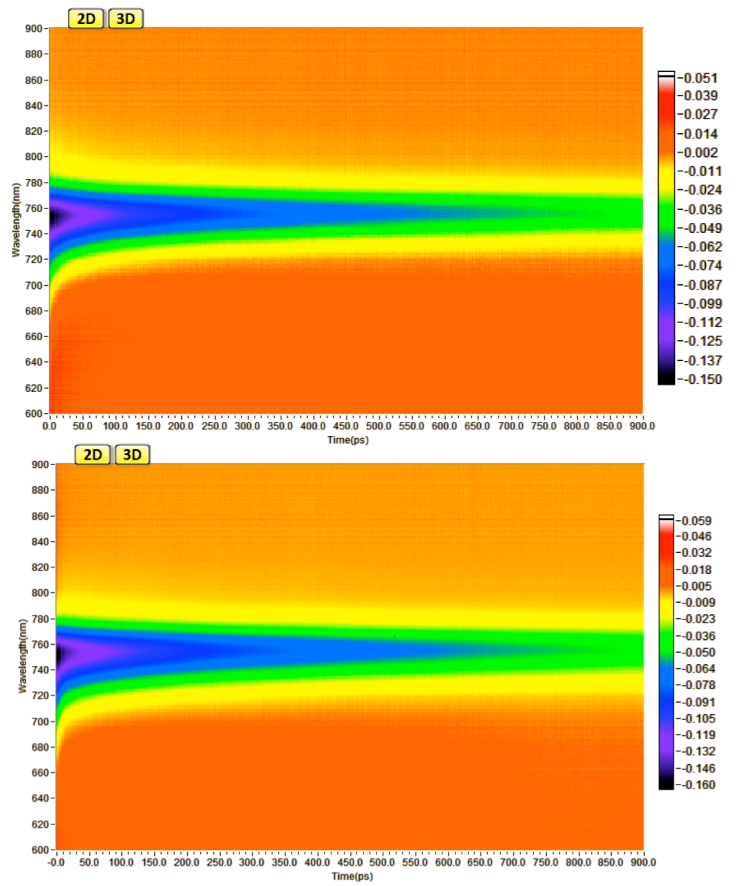
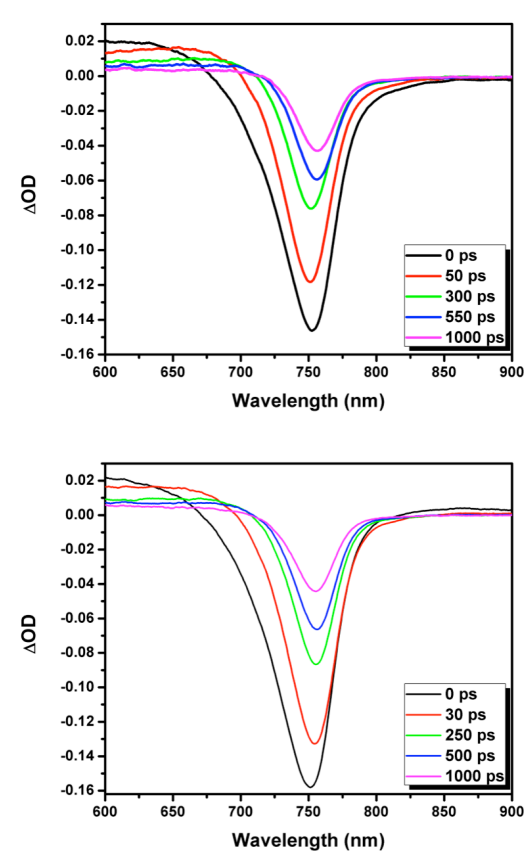

Figure 3. Typical transient absorption spectroscopy (TAS) 3D spectra of relative optical density $(\triangle \mathrm{OD})$ as a function of wavelength and time of PEDOT:PSS $/ \mathrm{CH}_{3} \mathrm{NH}_{3} \mathrm{PbI}_{3}$ (a) and PTAA $/ \mathrm{CH}_{3} \mathrm{NH}_{3} \mathrm{PbI}_{3}$ (b) structures, and corresponding $\Delta \mathrm{OD}$ vs. wavelength plots at various time delays following photoexcitation at $1026 \mathrm{~nm}$ with a pump fluence of $1.5 \mathrm{~mJ} \mathrm{~cm}$.

(a)

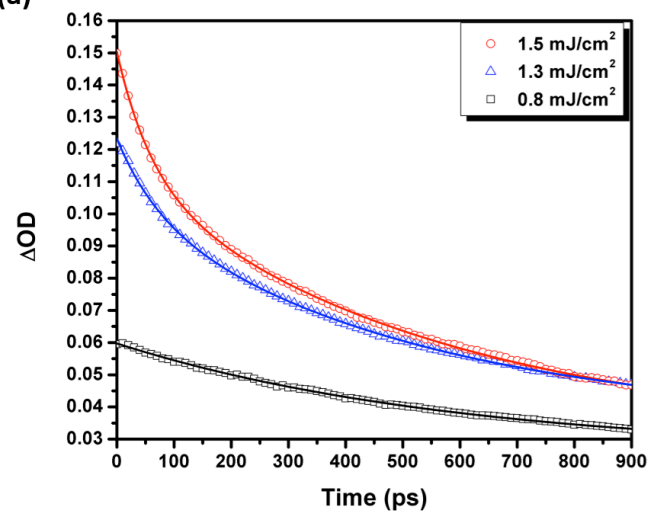

(b)

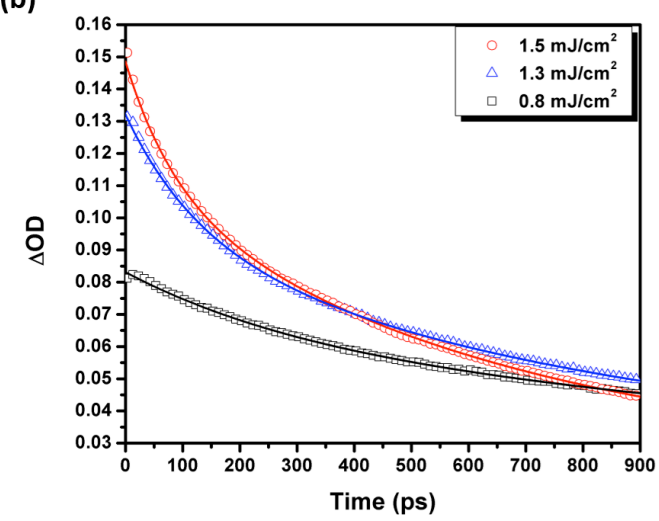

Figure 4. Transient band edge bleach kinetics (symbols) and their corresponding decay exponential fits (lines) for PEDOT:PSS/C $\mathrm{CH}_{3} \mathrm{NH}_{3} \mathrm{PbI}_{3}$ (a) and $\mathrm{PTAA} / \mathrm{CH}_{3} \mathrm{NH}_{3} \mathrm{PbI}_{3}$ configurations, photoexcited at $1026 \mathrm{~nm}$ with various pump fluencies. 
Table 1. Summary of the average photovoltaic characteristics of $\mathrm{CH}_{3} \mathrm{NH}_{3} \mathrm{PbI}_{3}$ based perovskite solar cells with PEDOT:PSS and PTAA polymers as hole transport layer.

\begin{tabular}{cccccc}
\hline $\begin{array}{c}\text { HTL } \\
\text { polymer }\end{array}$ & $\mathbf{J}_{\text {sc }}\left(\mathbf{m A ~ c m} \mathbf{~ c m}^{-2}\right)$ & $\begin{array}{c}\mathbf{J}_{\text {sc }} \text { Calculated } \\
\text { IPCE }\end{array}$ & $\mathbf{V}_{\text {oc }}(\mathbf{m V})$ & FF (\%) & PCE (\%) \\
\hline PEDOT:PSS & $20.79 \pm 0.39$ & 19.88 & $926 \pm 19$ & $65.46 \pm 1.03$ & $12.60 \pm 0.71$ \\
PTAA & $20.24 \pm 0.44$ & 19.15 & $1010 \pm 11$ & $76.67 \pm 0.69$ & $15.67 \pm 0.66$ \\
\hline
\end{tabular}

Table 2. Time components for PEDOT:PSS/CH $\mathrm{NH}_{3} \mathrm{PbI}_{3}$ and $\mathrm{PTAA} / \mathrm{CH}_{3} \mathrm{NH}_{3} \mathrm{PbI}_{3}$ architectures following exponential fitting (see text).

\begin{tabular}{ccccccccc}
\hline $\begin{array}{c}\text { Fluence } \\
\left.(\mathbf{m J ~ c m})^{-2}\right)\end{array}$ & \multicolumn{3}{c}{ PEDOT:PSS } & \multicolumn{5}{c}{ PTAA } \\
& $\boldsymbol{\lambda}_{\max }(\mathbf{n m})$ & $\boldsymbol{\tau}_{\mathbf{1}}(\mathbf{p s})$ & $\boldsymbol{\tau}_{\mathbf{2}}(\mathbf{p s})$ & $\boldsymbol{\tau}_{\mathbf{3}}(\mathbf{p s})$ & $\boldsymbol{\lambda}_{\max }(\mathbf{n m})$ & $\boldsymbol{\tau}_{\mathbf{1}}(\mathbf{p s})$ & $\boldsymbol{\tau}_{\mathbf{2}}(\mathbf{p s})$ & $\boldsymbol{\tau}_{\mathbf{3}}(\mathbf{p s})$ \\
\hline 0.8 & 755 & 305 & 596 & $3.9 \times 10^{6}$ & 755 & 218 & 523 & 3957 \\
1.3 & 753 & 57 & 335 & $1.5 \times 10^{5}$ & 751 & 22 & 125 & 790 \\
1.5 & 753 & 43 & 257 & $1.2 \times 10^{5}$ & 750 & 10 & 101 & 717 \\
\hline
\end{tabular}

Table 3. Charge carrier recombination rate constants for PEDOT:PSS/ $\mathrm{CH}_{3} \mathrm{NH}_{3} \mathrm{PbI}_{3}$ and PTAA/ $\mathrm{CH}_{3} \mathrm{NH}_{3} \mathrm{PbI}_{3}$ architectures following polynomial rate equation fitting (see text).

\begin{tabular}{ccccccc}
\hline $\begin{array}{c}\text { Fluence } \\
\left(\mathbf{m J ~ c m} \mathbf{~ c m}^{-2}\right)\end{array}$ & \multicolumn{3}{c}{ PEDOT:PSS } & \multicolumn{3}{c}{ PTAA } \\
& $\mathrm{k}_{3}\left(\mathrm{~cm}^{6} \mathrm{~s}^{-1}\right) \pm 0.4$ & $\mathrm{k}_{2}\left(\mathrm{~cm}^{3} \mathrm{~s}^{-1}\right) \pm 0.2$ & $\mathrm{k}_{1}\left(\mu \mathrm{s}^{-1}\right) \pm 0.1$ & $\mathrm{k}_{3}\left(\mathrm{~cm}^{6} \mathrm{~s}^{-1}\right) \pm 0.4$ & $\mathrm{k}_{2}\left(\mathrm{~cm}^{3} \mathrm{~s}^{-1}\right) \pm 0.2$ & $\mathrm{k}_{1}\left(\mu \mathrm{s}^{-1}\right) \pm 0.1$ \\
\hline 0.8 & - & $3.3 * 10^{-12}$ & $3.8^{*} 10^{-7}$ & - & $4 * 10^{-13}$ & $1.5^{*} 10^{-7}$ \\
1.3 & $3.0^{*} 10^{-14}$ & $1.8^{*} 10^{-11}$ & $2.1^{*} 10^{-6}$ & $1.8^{*} 10^{-14}$ & $0.9^{*} 10^{-11}$ & $1.8^{*} 10^{-6}$ \\
1.5 & $7.3 * 10^{-14}$ & $3.6^{*} 10^{-11}$ & $4.4^{*} 10^{-6}$ & $3.8^{*} 10^{-14}$ & $1.7^{*} 10^{-11}$ & $3.1^{*} 10^{-6}$ \\
\hline
\end{tabular}




\section{TOC GRAPHIC:}

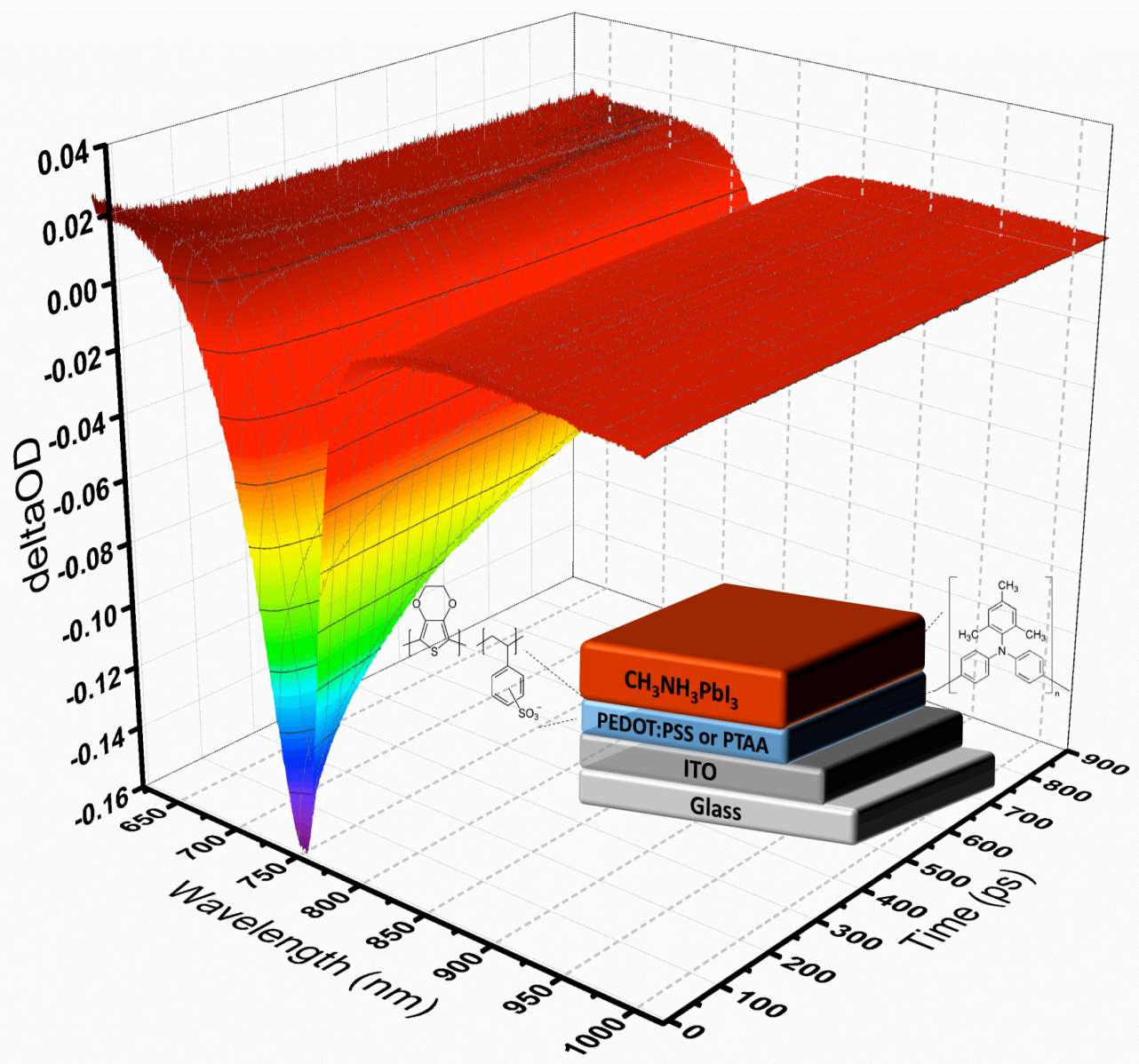

